\title{
Radiofrequencies and Proctology: A Difficult Marriage
}

\author{
V. Filingeri G. Gravante \\ Department of Surgery, University of Rome Tor Vergata, Rome, Italy
}

Dear Sir,

In a recent article Gupta [1] outlined an important issue of radiofrequency surgery in the field of proctology. New technologies have been widely adopted in hemorrhoid treatment with the great result of improving our understanding of the anatomy and the pathophysiology of the disease. However, in many cases the initial favorable attention and emphasis have not been critically studied with regard to the long-term results in terms of complications and recurrences. Stapler hemorrhoidopexy, for example, has gained an immediate consensus but, with time, serious postoperative complications have been seen that sometimes even jeopardize the patient's life [2]. Doppler-guided hemorrhoidal artery ligation has given promising results especially in finding and ligating all the hemorrhoidal vessels, but it is fundamentally a conservative treatment and not a technique of hemorrhoidectomy. For these reasons, authors recommended it only as an option for patients in whom operative hemorrhoidectomy is contraindicated [3]. Only one randomized study compared this technique with hemorrhoidectomy, and the positive results in terms of recurrences still have to be validated by a longer follow-up [4].

Radiofrequency surgery is a new tool in proctology and is still frequently misunderstood and ignored by most of the proctologists. In conjunction with Gupta, our group has gained wide experience experimenting with radiofrequency surgery in every major proctologic disease (hemorrhoids, anal fissures and anal fistulas), and we have compared this technology with current gold standards in randomized clinical trials [58]. In our studies we obtained positive results in terms of postoperative recovery, reduction of pain, and return to normal activity. The most important characteristic that makes radiofrequency surgery different from other methods is its cutting-coagulating ability developed through the use of radiowaves. These waves generate a tissue temperature that does not exceed $65^{\circ} \mathrm{C}$ and is assimilated to a 'cold' cut. This advantage is important when operating on delicate tissue such as the anal canal mucosa because the atraumatic nature of the cut allows a dramatic reduction in tissue edema with subsequent improvement in postoperative pain. Moreover, histological analysis has shown that the healing processes are optimal and faster than normal with fewer longterm complications. Last but not least, radiofrequency surgery does not alter the basic technique of the operation and, for this reason, the postoperative recurrences of classic hemorrhoidectomy (both open and closed) are the same, sphincterotomy, fistulectomy or fistulotomy, but the operation is easier and faster.

For this reason, since 1993 we have usually used radiofrequencies in our clinical practice, and the results obtained encourage us to continue.

\section{References}

1 Gupta PJ: Hemorrhoidal ablation and fixation: an alternative procedure for prolapsing hemorrhoids. Digestion 2005;72:181-188.

2 Filingeri V, Gravante G: Pneumoretroperitoneum, pneumomediastinum and subcutaneous emphysema of the neck after stapled hemorrhoidopexy. Tech Coloproctol 2005;9:86.

3 Sohn N, Aronoff JS, Cohen FS, et al: Transanal hemorrhoidal dearterialization is an alternative to operative hemorrhoidectomy. Am J Surg 2001;182:515-519.

4 Bursics A, Morvay K, Kupcsulik P, et al: Comparison of early and 1-year follow-up results of conventional hemorrhoidectomy and hemorrhoid artery ligation: a randomized study. Int J Colorectal Dis 2004; 19:176-180.

5 Filingeri V, Rosati R, Gravante G, et al: Milligan-Morgan hemorrhoidectomy with a radiofrequency scalpel. Minerva Chir 2003;58:355359 .

6 Filingeri V, Gravante G, Baldessari E, et al: Prospective randomized trial of submucosal hemorrhoidectomy with radiofrequency scalpel vs. conventional Parks' operation. Tech Coloproctol 2004;8:31-36.

7 Filingeri V, Gravante G: A prospective randomized trial between subcutaneous lateral internal sphincterotomy with radiofrequency bistoury and conventional Parks' operation in the treatment of anal fissures. Eur Rev Med Pharmacol Sci 2005;9:175-178.

8 Filingeri V, Gravante G, Baldessari E, et al: Radiofrequency fistulectomy vs. diathermic fistulotomy for submucosal fistulas: a randomized trial. Eur Rev Med Pharmacol Sci 2004; 8:111-116.

\section{KARGER}

Fax +4161306 1234 E-Mail karger@karger.ch www.karger.com
(C) 2005 S. Karger AG, Basel 0012-2823/05/0724-0261\$22.00/0

Accessible online at: www.karger.com/dig
Dr. Gianpiero Gravante

Department of Surgery, University of Rome Tor Vergata

via U. Maddalena 40/a

IT-00043 Ciampino, Rome (Italy)

Tel. +39 348 6701961, Fax +3906 233216592, E-Mail ggravante@hotmail.com 


\section{Reply}

\section{Pravin J. Gupta}

Fine Morning Hospital and Research Center, Gupta Nursing Home, Nagpur, India

I agree with Filingeri and Gravante that the introduction of new techniques and technologies in medical science is both stimulating and controversial. With regard to the radiofrequency device, surgeons and proctologists have used this instrument sparingly, and then too more out of curiosity than a serious attempt to utilize its vast potentials. The reason perhaps might be that they were satisfied with the results of the conventional techniques they used, or were not sure about the use of this tool in anorectal surgery for want of sufficient literature on the subject.

Radiofrequency proctological procedures are simple to perform with many advantages over the more traditional tech- niques. The procedures take less operative time, postoperative recovery is accelerated, and the incidences of complications are negligible. Most of the procedures are less painful in the postoperative course, help in early return to work and result in rapid healing of wounds. Radiofrequency surgery facilitates performance of procedures like anal fistula, hemorrhoids, pilonidal sinuses and various other anorectal surgeries [1]. The surgical techniques are easy to learn, safe and effective. The procedures are costeffective as no expenses of recurring nature are incurred. The radiofrequency device, having a versatile use in various surgical procedures, can prove handy for practicing surgeons [2].

\section{References}

1 Gupta PJ: Use of radiofrequency in the treatment of minor anal pathology. Acta Chir Belg 2004; 104:313-317.

2 Gupta PJ: Radio surgery: a new tool in proctology practice. Bratisl Lek Listy 2004;105:270276. 